\title{
CARACTERIZAÇÃO PETROGRÁFICA E GEOQUÍMICA DE ROCHAS ANFIBOLÍTICAS E METAMÁFICAS ASSOCIADAS ÀS FAIXAS METAMÓRFICAS AMPARO E ITAPIRA NA REGIÃO NORDESTE DE SÃO PAULO
}

\author{
MARCOS AURÉLIO FARIAS DE OLIVEIRA', ANTENOR ZANARDO' ${ }^{1}$, ANA PAULA LAZARINI², \\ ALESSANDRO HENRIQUE MEDEIROS SILVA ${ }^{3} \&$ ANTÔNIO JOSÉ RANALLI NARDY ${ }^{1}$
}

\begin{abstract}
PETROGRAPHICAND GEOCHEMICAL CHARACTERIZATION OF AMPHIBOLITEAND METAMAFIC ROCKS IN THE AMPARO AND ITAPIRA METAMORPHIC BELTS, NORTHEAST SÃO PAULO STATE, BRAZIL Metamafic and metaultramafic rocks and amphibolite are common throughout the region of occurrence of the Amparo and Itapira metamophic complexes. A regional study of these rocks is presented for an area between the cities of Socorro and Amparo in the south and Monte Sião and Itapira in the north. Field and petrographic data indicate that these rocks may be classified into four groups, represented by hornblende schist, amphibolite, orthopyroxene amphibolite and metaultramafic units. The last one is interpreted as a cumulate based on petrographic features and olivine and pyroxene contents. Geochemical data show evidences of magmatic derivation, and a tholeiitic sub alkaline composition. Sub alkaline basalt, andesi basalt and picro basalt or picrite can be recognized in the classification diagrams. Some samples show $\mathrm{MgO}$ contents between 6,30 and 8,41\% and are grouped as low $\mathrm{MgO}(\mathrm{MBM})$ and others have $\mathrm{MgO}$ contents between 12,31 and $28,81 \%$ and are grouped as high $\mathrm{MgO}$ (MAM). The sample with $28,81 \% \mathrm{MgO}$ is the metaultramafic that is considered to be a cumulate, with very high $\mathrm{Cr}$ and $\mathrm{Ni}$ contents. The rocks of the MAM group present in the diagrams trends of magmatic differentiation that are not confirmed by fractional crystallization tests. Besides the high Ce anomalies may be related to process involving the continental crust in the generation of the protolith from the mantle or during emplacement. Also the spidergrams show that these rocks have been affected by the continental crust related to the mantle source or to the intrusion time. As an example are the anomalies of $\mathrm{Sr}, \mathrm{K}, \mathrm{Rb}$ and $\mathrm{Ba}$. The metamorphic effects are also evident when some discrepant signatures are observed in spidergrams of incompatible elements. Even so, it is still possible to recognize E-MORB type signatures shown by the multi element diagrams for the metamafic and amphibolite, with the ultramafic being more primitive.
\end{abstract}

Keywords: metamafic-metaultramafic rocks, geochemistry, petrogenesis, Amparo Complex, Itapira Group.

Resumo Ocorrências de rochas metamáficas, metaultramáficas e anfibolitos são comuns em toda a região por onde se distribuem os metamorfitos dos complexos Amparo e Itapira. Estudo regional sobre essas ocorrências é apresentado para uma área compreendida entre as cidades de Socorro e Amparo, ao sul, e entre Monte Sião e Itapira, ao norte. Dados de campo e petrográficos indicam que essas rochas podem ser reunidas em quatro agrupamentos representados por hornblenda xisto, anfibolito, ortopiroxênio anfibolito e metaultramáfica, sendo este último interpretado como cumulato pelas feições texturais e concentração de olivina e ortopiroxênio. Dados geológicos, petrográficos e litogeoquímicos evidenciam uma derivação magmática para as amostras estudadas, com material pretérito de composição subalcalina e toleítica, podendo ser classificadas como basalto subalcalino, andesi basalto e picro basalto ou picrito. Os teores de $\mathrm{MgO}$ permitem a subdivisão em dois grupos: baixo magnésio (MBM), com teores de $\mathrm{MgO}$ entre 6,30 e $8,41 \%$ e alto magnésio (MAM), com teores desse óxido entre 12,31 e 28,81\%. A amostra que contem 28,81\% de MgO é a metaultramáfica que está sendo interpretada como cumulato e que apresenta altos teores de $\mathrm{Cr}$ e $\mathrm{Ni}$. As amostras do agrupamento MAM parecem definir trends de diferenciação magmática o que não se confirma em um teste de cristalização fracionada. Além disso, as fortes anomalias de $\mathrm{Ce}$, que elas exibem, podem relacionar-se a processos envolvendo a crosta continental, quer na geração do protolito a nartir do manto ou então na fase de intrusão. Também os diagramas multielemento deixam transparecer que em algum momento essas

-has parecem ter sido afetadas pala crosta continental, quer na etapa referente à fonte mantélica quer na etapa de intrusão, sendo .emplos disso as anomalias de $\mathrm{Sr}, \mathrm{K}$, Rb e Ba. Os efeitos do metamorfismo também são evidenciados quando se observam padrões de distribuição aleatórios para as amostras do agrupamento MBM em diagramas multielemento. Por fim, a análise desses diagramas revela uma assinatura E-MORB, para a metamáfica e o anfibolito, com características mais primitivas para a metaultramáfica (cumulato)

Palarras-chave: metamáfica-metaultramáfica, geoquímica, petrogênese, complexo Amparo e Grupo Itapira.

INTRODUÇÃO O presente trabalhoé parte de um programa de estudos petrográficos, litoquímicos, geotermobarométricos e isotópicos de anfibolitos e metamáficas inseridas em cinturões metamórficos de parte da região sudeste e sul do Brasil, abrangendo desde o sul de Minas Gerais até o norte do Paraná. Pretende-se com este estudo um conhecimento melhor da petrografia, geoquímica e condições de pressão e temperatura do evento metamórfico que afetou essas unidades e, a partir daí, tentar uma modelagem da sua gênese e consequentemente do conjunto ou conjuntos metamórficos encaixantes.

No presente artigo é feito um apanhado geral das ocorrências de anfibolitos e metamáficas na área situada entre as cidades de Socorro e Amparo, a sul e Monte Sião e Itapira, a norte. Realizouse uma classificação petrográfica e litoquímica dos tipos cadastrados, incluindo ETR, visando, por essa caracterização, definir critérios distintivos que permitam relacioná-los ao embasamento ou à

1 - Instituto de Geociências e Ciências Exatas - UNESP, Avenida 24 A, 1515, Caixa Postal 178, CEP 13506-900, Rio Claro, SP, maurelio@rc.unesp.br, 2 - Pós-Graduação em Geociências. Instituto de Geociências e Ciências Exatas - UNESP, Av 24 A, 1515, CEP 13506-90), Rio Claro, SP.

3 - AngloGold, Rua Cássio Magnani, 31, CEP 34000-(0)0, Nova Lima, MG. 
seqüência supra crustal, entidades tectono-metamórficas componentes dessa área.

A evolução geológica da região é complexa e onde os anfibolitos e metamáficas ocorrem associados tanto ao embasamento (Complexo Amparo) como à sequiência metavulcanossedimentar do Grupo (Complexo) Itapira. As paragêneses de metamorfismo dessas rochas é variável, com litotipos da fácies anfibolito e outros da fácies granulito. Petrograficamente ocorrem diversos tipos desde praticamente monominerálicos (mais de $95 \%$ de anfibólio) até associações complexas, com piroxênio e granada.

CONTEXTOGEOLÓGICO Na área estudada ocorrem associações íntimas de rochas ortoderivadas do embasamento (Complexo Amparo) e da seqüência metavulcanossedimentar (Grupo ou Complexo Itapira), ambas de médio a alto grau metamórfico, a ponto de muitas vezes tornar-se difícil o reconhecimento de sua posição estratigráfica. O fator preponderante nesse caso é uma tectônica que gerou grande concentração de zonas de cisathamento empinadas, destrais, que colocaram, lado a lado, faixas estreitas e alongadas de rochas do embasamento e da sequiência supracrustal, e que participam de uma estrutura de empurrão descrita por Campos Neto et al. (1984) como Nappe de Empurrão Socorro-Guaxupé. Os primeiros trabalhos sobre essa áreacomo, dentre outros, os de Wernick (1967), Ebert (1968, 1971)e Wernick \& Penalva (1973), não distinguiram essas unidades como hoje caracterizadas. Dados geocronológicos mostram que estas rochas possuem idades que variam do Arqueano ao Neoproterozóico (Wernick 1978, Artur 1980, Wernick et al. 1976, Tassinari \& Campos Neto 1988, Tassinari et al. 2001, Fetter et al. 2001). Geotectonicamente a região está contida nos domínios da faixa Alto Rio Grande (Hasui \& Oliveira 1984) e da Nappe Socorro-Guaxupé (Campos Neto et al. 1984, Campos Neto (1985).

As ocorrências de anfibolitos e metamáficas estão intercalads em nas diversas rochas da área estudada, com formas tabulares a lenticulares, cisalhadas e fragmentadas, com larguras centimétricas a métricas, orientadas e alongadas segundo NNE-SSW. Um perfil de Socorro e Amparo ocorem os seguintes agrupamentos de rochas: (Fig. 1)

- Íntimas associações de gnaisse mangerítico, charnockítico e enderbítico; granulito básico e piroxênio anfibolito ocorrem intercalados a sul de Socorro. Este agrupamento é limitado à oeste, próximo a Socorro, por uma zona de falha de cavalgamento, parte da Nappe Socorro-Guaxupé de Campos Neto et al. (1984).

- Gnaisses, migmatitos e granitos sintectônicos com intercalações de biotita hornblenda gnaisse, anfibolito, quartzito, gondito e rocha metaultramáfica. O quartzito se destaca por sustentar serras alongadas segundo $\mathrm{NE}$.

- Paragnaisse arcosiano, grauváquico, às vezes migmatizado, mica xisto e quartzito, anfibolito e rocha ultramáfica, com intercalações subordinadas de ortognaisse granítico a granodiorítico.

Gnaisse e migmatito cinzento a róseo, homogêneo a bandado, granítico a granodiorítico, com intercalações de anfibólio gnaisse e rocha ultramáfica.

- Migmatito com estruturas diversas, ortognaisse, metamáfica e metaultramáfica.

CARACTERIZAÇÃO PETROGRÁFICA Nesse contextoprocedeu-se à coleta sistemática de amostras de anfibolitos e metamáficas, precedida de revisão das amostragens de projetos anteriores realizados na área. A localização das amostras ora descritas está indicada na figura 1 , observando-se que existem tipos associados ao pacote metassedimentar, aos migmatitos e aos granulitos. O estudo de mais de duas dezenas de lâminas de anfibolitos permitiu agrupá-los nos seguintes tipos:

Hornblenda xisto - HXO - (amostras ALS 10, SOR 13, SOR 14, SOR 15). São rochas foliadas com mais de $80 \%$ de anfibólio modal, possuem cores escuras, verde a preto, e texturas nematoblástica ou nematoblástica e granoblástica. $\mathrm{O}$ anfibólioé hornblenda, com pleocroísmo fraco a médio de incolor a verde pardo ou verde azulado pálido. Cummingtonita pode ocorrer. Os demais constituintes compreendem labradorita parcialmente saussuritizada e corroída e clinopiroxênio em fenoblastos corroídos e transformados em hornblenda verde. Titanita e opacos são acessórios e epidoto e actinolita secundários. Observam-se por vezes lentes milimétricas, rompidas, concordantes com a foliação, compostas por plagioclásio e clinopiroxênio (gabro) ou apenas quartzo. Lazarini (2000), por meio de química mineral dessas rochas, determinou a presença de actinolita, Mg-hornblenda e Mg-cummingtonita.

Anfibolito - ANF - (amostras ALS-1, ALS-9, AMG-4, AMG-5, SOR-7, SOR-16, SOR-21). Éo litotipo mais abundante. São rochas foliadas, com textura nematobástica a granoblástica, freqüentemente afetadas por cataclase. A granulação é dominante fina a média. Hornblenda é o mineral predominante, com pleocroísmo forte de verde pálido a verde pardo e a verde azulado. Os cristais são, por vezes, zonados (manchados), com núcleo esverdeado e borda mais pardas ou azuladas. O plagioclásio é andesina e constitui até $50 \%$ dessas rochas. Diopsídio está presente em até $15 \%$ e seus cristais estão corroídos, fraturados e parcialmente alterados. Os demais constituintes compreendem quartzo, microclínio, granada, biotita, titanita, epidoto e opacos.

Metaultramáfica - MUM - (amostra ALS-2). Ocorrências de olivina-ortopiroxênio anfibolito, olivina metaortopiroxenito e metaharzburgito foram registradas próximo à cidade de Lindóia, associadas a quartzito, e na região de Arcadas por Pellogia (1990). A ocorrência de Lindóia, ora estudada, é maciça, fraturada, textura granoblástica inequigranular fina a média. O principal componente é a olivina (até $40 \%$ ), de até $7 \mathrm{~mm}$ de diâmetro e com fraturas preenchidas por serpentina, seguida de bronzita (até $40 \%$ ) em prismas de até $5 \mathrm{~mm}$ de comprimento. Os demis constituintes compreendem hornblenda tremolítica a Mg-hornblenda (15\%), com pleocroísmo fraco de incolor a levemente pardo, flogopita, espinélio verde pardo (picotita), todos inferiores a $1 \mathrm{~mm}$. Serpentina, talco e clorita são secundários. A composição mineral e as feições texturais sugerem que essas rochas podem representar cumulatos de olivina e piroxênio. Os dados químicos dos minerais foram obtidos em Lazarini (2000).

Ortopiroxênio anfibolito-OPA - (granulito máfico, amostras ALS6 E ALS-7). Ocorre na porção sul da faixa charnockítica de Socorro (Fig. 1). São rochas de discretamente foliadas, cinza-esverdeado escuro a pretas, e de textura milonítica granoblástica, contendo anfibólio cálcico (pargasita), marron, fortemente pleocróico, em teores modais de 30 e $40 \%$, e plagioclásio (bitownita) às vezes simplectítico, intercrescido com granada ou clinopiroxênio (salita), e proporções entre 25 e $50 \%$. Os demais minerais compreendem bronzita (8-16\%), granada (5 a 8\%) e clinopiroxênio (4 a 16\%). Os dados de química mineral são de Lazarini (2000).

O metamorfismo que afetou essas rochas é de fácies anfibolito alto a granulito. No caso do anfibolito, do hornblenda xisto e da 


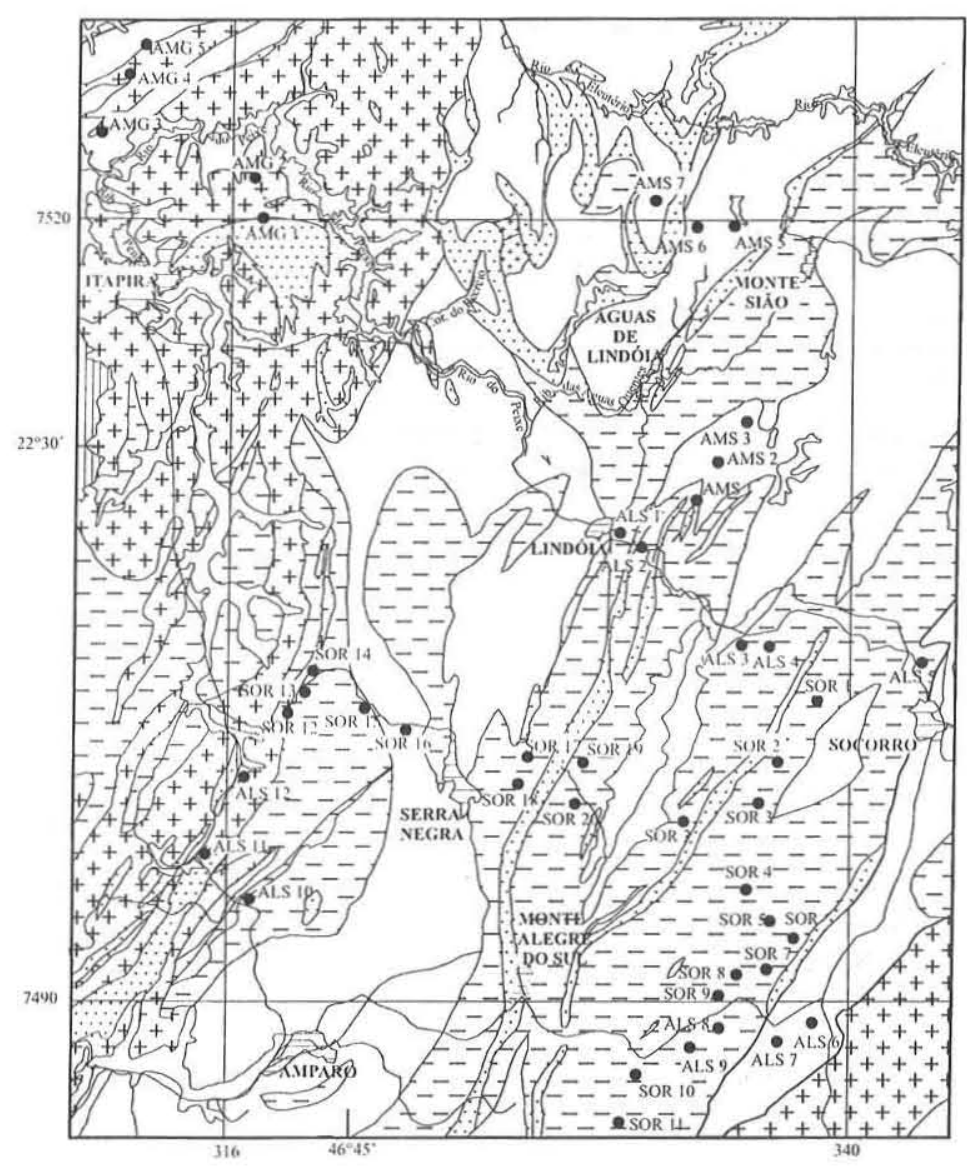

LEGENDA

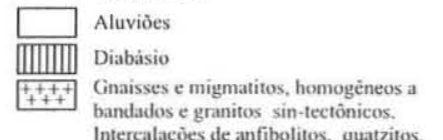
bandados e granitos sin-tectónicos.
Intercalaçòes de anfibolitos, quatzitos. calcio-silicáticas, gonditos e ultramáficas.

Gnaisses charnokiticos, granuliticos e granitóides associados; homblenda gnaisses e anfibolitos.

带罚 Ortoquartzitos intercalados com xistos psamo-peliticos.

Xistos, gnaisses, migmatitos e granitos sintectônicos. Intercalaçòes de rochas calcio-silicáticas, quartzitos, anfibolitos. gonditos $\mathrm{e}$ ultramáficas.

$\square$ Xistos, gnaisses e migmatitos, homogeneneos a bandados, graniticos a granodioriticos, com intercalaçòes de anfibolitos $\mathrm{e}$ ultramáficas.

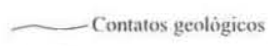

$\longrightarrow$ Drenagem

Rodovias Pavimentadas Fstaduais

$\stackrel{3}{3}$ Cidades

- Pontos amostrados

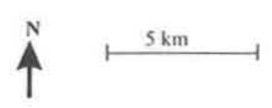

Figura 1 - Mapa geológico simplificado da região de Itapira, Amparo e Socorro, SP.

metaultramáfica as associações minerais indicam condições de fácies anfibolito. Se considerarmos um protólito rico em piroxênio e plagioclásio, as transformações ocorridas para desenvolver hornblenda nessas rochas implicariam na adição de fluido aquoso. Já no granulito máfico, as transformações metamórficas devem ter ocorrido sob condições de $\mathrm{P}_{\mathrm{H} 2 \mathrm{O}}$ limitada para estabilizar o piroxênio. Os intercrescimentos simplectíticos de granada, piroxênio e plagioclásio indicam condições de pressão superiores a 10 kbar (Freitas 2000).

DADOS GEOQUÍMICOS A partir dos estudos petrográficos foram selecionadas amostras para análises quimicas no LABOGEO do DPM, IGCE-UNESP de Rio Claro. Um total de 16 exemplares foram analisados, segundo os métodos descritos em Nardy et al. (1997), por fluorescência de raios-X para os óxidos de elementos maiores $\mathrm{SiO}_{2}, \mathrm{TiO}_{2} \mathrm{Al}_{2} \mathrm{O}_{3}, \mathrm{Fe}_{2} \mathrm{O}_{3}, \mathrm{FeO}, \mathrm{MnO}, \mathrm{MgO}, \mathrm{CaO}, \mathrm{Na}_{2} \mathrm{O}$, $\mathrm{K}_{2} \mathrm{O}_{2} \mathrm{P}_{2} \mathrm{O}_{5}$ e os elementos traços $\mathrm{Cr}$, Ni, Rb, $\mathrm{Sr}, \mathrm{Zr}$, Y, Nb e Ba, estes analisados em pastilhas prensadas sob $30 \mathrm{t} / \mathrm{cm}^{2}$. Os ETR foram determinados em oito amostras por espectrometria de ICP-AES, segundo o método descrito em Malagutti et al. (1998). Os resultados constam na Tabela 1.

Considerando que as amostras são de rochas submetidas a metamorfismo, e possivelmente metassomatismo, para verificar os efeitos destes processos sobre a sua composição química os resultados foram inseridos no diagrama de Miyashiro (1975) (Fig. 2), que emprega as concentrações de dois elementos móveis (Na e
K). Do diagrama conclui-se que a composição das amostras não foi significativamente afetada por estes processos.

Os diagramas de variação (Figs. 3 e 4 ) revelam, em exame preliminar, a existência de dois grupos distintos. Um tem concentrações de $\mathrm{MgO}$ entre 6,30e 8,14\%, e aqui designado de baixo magnésio (MBM), e outro tem $\mathrm{MgO}$ entre 12,31 e 28,81\%, denominado de alto magnésio (MAM). $\mathrm{O}$ valor de $\mathrm{MgO}=28,81 \%$ corresponde à amostra ALS 2, metaultramáfica e possível cumulato, e cujos teores de Cr são elevados (>3000 ppm) e de $\mathrm{Ni}$ (>2000 ppm). Ambos grupos têm características petrográficas distintas, em que as amostras do MBM são representadas por anfibolito e ortopiroxênio anfibolito, e as do MAM por hornblenda xisto e metaultramáfica. As amostras do grupo MAM, com $16,5 \%$ de variação máxima de $\mathrm{MgO}$, distribuem-se (Figs. 3 e 4) ao longo de alinhamentos, especialmente com respeito a $\mathrm{SiO}_{2}, \mathrm{TiO}_{2}, \mathrm{Al}_{2} \mathrm{O}_{3}, \mathrm{CaO}, \mathrm{Cr}$, Ni, $\mathrm{Rb}$ e Zr que podem indicar trends de diferenciação. O mesmo não ocorre com as amostras do grupo $\mathrm{MBM}$, nas quais há grandes variações de $\mathrm{SiO}_{2}, \mathrm{TiO}_{2}, \mathrm{FeOt}, \mathrm{CaO}, \mathrm{Na}_{2} \mathrm{O}, \mathrm{K}_{2} \mathrm{O}, \mathrm{P}_{2} \mathrm{O}_{5}, \mathrm{Ba}, \mathrm{Rb}, \mathrm{Zr}$ e Nb ao longo de pequeno intervalo de $\mathrm{MgO}(1,84 \%)$.

Os dados geológicos e petrográficos sugerem que os protólitos das amostras estudadas foram magmáticos (Fig. 5), de filiação subalcalina e toleítica (Figs. 6 e 7). Na figura 7, os agrupamentos MAM e MBM distribuem-se no campo dos toleítos, com forte tendência de enriquecimento em $\mathrm{Fe}$, em especial nas amostras do agrupamento MBM. Observe-se que, embora haja uma diferença significativa na concentração de $\mathrm{MgO}$ entre os dois grupos, am- 
Tabela I - Concentrações de elementos maiores, menores, traços e terras raras de rochas anfibolíticas e metamáficas estudadas.

\begin{tabular}{|c|c|c|c|c|c|c|c|c|c|c|c|c|c|c|c|c|}
\hline & ALS 1 & $\Lambda \mathrm{LS} 2$ & ALS 6 & ALS 7 & ALS 9 & $\begin{array}{c}\text { ALS } \\
10\end{array}$ & SOR 7 & $\begin{array}{c}\text { SOR } \\
13 \mathrm{a}\end{array}$ & $\begin{array}{c}\text { SOR } \\
13 b\end{array}$ & $\begin{array}{c}\text { SOR } \\
13 d\end{array}$ & $\begin{array}{c}\text { SOR } \\
14\end{array}$ & $\begin{array}{c}\text { SOR } \\
15\end{array}$ & $\begin{array}{c}\text { SOR } \\
16\end{array}$ & $\begin{array}{c}\text { SOR } \\
21\end{array}$ & $\begin{array}{c}\text { AMG } \\
5\end{array}$ & $\begin{array}{c}\mathrm{AMG} \\
4\end{array}$ \\
\hline Rocha & ANF & MUM & OPA & OPA & $\mathrm{ANF}$ & $\mathrm{HXO}$ & $\mathrm{ANF}$ & $\mathrm{HXO}$ & $\mathrm{HXO}$ & $\mathrm{HXO}$ & $\mathrm{HXO}$ & $\mathrm{HXO}$ & ANF & ANF & ANF & ANF \\
\hline $\mathrm{SiO}_{2}$ & 54,90 & 45,20 & 42,98 & 47,23 & 48,29 & 50,38 & 48,01 & 51,20 & 54,25 & 48,98 & 50,60 & 48,63 & 55,53 & 50,17 & 47,69 & 50,36 \\
\hline $\mathrm{TiO}_{2}$ & 0.63 & 0.16 & 1,54 & 2,07 & 1,31 & 0,64 & 1,38 & 0.62 & 0,78 & 0,81 & 0,83 & 0,70 & 0,62 & 0,93 & 1.56 & 0,85 \\
\hline $\mathrm{Al}_{2} \mathrm{O}_{3}$ & 14.87 & 5,18 & 15,35 & 13,56 & 14,64 & 4,61 & 15,11 & 5,19 & 7,93 & 6.53 & 6,41 & 5,75 & 12,38 & 15,36 & 14,28 & 15.76 \\
\hline $\mathrm{FeO}$ & 9.11 & 8,65 & 12,49 & 16,85 & 15,97 & 13,24 & 12,20 & 12,43 & 11,22 & 14,11 & 13,08 & 13.75 & 10,28 & 12,07 & 16,43 & 10,80 \\
\hline $\mathrm{MnO}$ & 0,17 & 0.11 & 0,15 & 0.28 & 0,22 & 0.20 & 0,21 & 0,19 & 0,18 & 0.20 & 0,18 & 0,22 & 0.18 & 0.19 & 0,21 & 0,16 \\
\hline $\mathrm{MgO}$ & 7.01 & 28,81 & 6.83 & 6.85 & 7,37 & 16.74 & 8.14 & 16,16 & 12,31 & 17,82 & 14,57 & 18,69 & 7,96 & 7,38 & 6.30 & 7,32 \\
\hline $\mathrm{CaO}$ & 10,90 & 4,62 & 16,27 & 10,85 & 10,35 & 10,18 & 12,73 & 11,86 & 11,52 & 9,36 & 11.44 & 9,51 & 9,38 & 12,49 & 9,34 & 9.72 \\
\hline $\mathrm{Na}_{2} \mathrm{O}$ & 1.51 & 0,23 & 1,32 & 1,48 & 1,00 & 0,69 & 1,62 & 0,38 & 1,98 & 0,58 & 0,63 & 0,81 & 2,61 & 1,44 & 0,91 & 2.61 \\
\hline $\mathrm{K}_{2} \mathrm{O}$ & 0.13 & 0,05 & 0.43 & 0,25 & 0,19 & 0,07 & 0,35 & 0.07 & 0,17 & 0,10 & 0.20 & 0,11 & 0,89 & 0,15 & 1,27 & 1.13 \\
\hline $\mathrm{P}_{2} \mathrm{O}_{5}$ & 0.07 & 0,01 & 0,24 & 0,30 & 0,12 & 0,14 & 0,11 & 0,06 & 0,07 & 0,11 & 0,07 & 0,07 & 0,06 & 0,08 & 0,16 & 0,09 \\
\hline LOI & 1.27 & 6,06 & 2.10 & 1,04 & 0,87 & 2,90 & 1,02 & 1,03 & 0,60 & 0.97 & 1,75 & 0,94 & 0,93 & 0,47 & 1,12 & 1,26 \\
\hline SOMA & 100.57 & 99.29 & 99,70 & 100,76 & 100,33 & 99,79 & 100,88 & 99,19 & 101,01 & 99.57 & 99,76 & 99,18 & 100,82 & 101,27 & 99,27 & 100,06 \\
\hline $\mathrm{Cr}$ & 169 & 3494 & 155 & 72 & 200 & 2003 & 330 & 1554 & 799 & 1674 & 1384 & 1512 & 730 & 417 & 221 & 229 \\
\hline $\mathrm{Ni}$ & 124 & 2647 & 108 & 123 & 121 & 1247 & 100 & 470 & 2.35 & 925 & 422 & 924 & 224 & 177 & 149 & 141 \\
\hline $\mathrm{Rb}$ & 4 & 3 & 14 & 7 & 6 & 9 & 10 & 1 & 2 & 2.3 & 5 & 1 & 18 & 8 & 60 & 46 \\
\hline Sr & 73 & 19 & 1394 & 85 & 85 & 83 & 150 & 44 & 84 & 37 & 53 & 78 & 122 & 215 & 145 & 232 \\
\hline Ba & 2 & 18 & 212 & 6.5 & 59 & 3.3 & 19 & 17 & 18 & - & 7 & 16 & 58 & 18 & 252 & 435 \\
\hline $\mathrm{Nb}$ & 6 & 5 & 5 & 16 & 8 & 7 & 7 & 3 & 4 & 13 & 6 & 5 & 4 & 4 & 9 & 6 \\
\hline $\mathrm{Zr}$ & 37 & 8 & 91 & 143 & 54 & 57 & 84 & 41 & 46 & 59 & 64 & 38 & 35 & 50 & 83 & 69) \\
\hline $\mathrm{Y}$ & 16 & 8 & 19 & 34 & 170 & 193 & 22 & 19 & 19 & 33 & 21 & 17 & 28 & 19 & 23 & 25 \\
\hline $\mathrm{La}$ & - & 1,40 & 11,24 & 15,60 & - & 87,60 & - & 4,80 & - & 26,50 & - & - & - & 2,93 & 4,05 & - \\
\hline $\mathrm{Ce}$ & - & 1,24 & 26,38 & 38.29 & - & 27,30 & - & 7,62 & - & 15,10 & - & - & - & 7,49 & 10,53 & - \\
\hline $\mathrm{Nd}$ & - & 0,89 & 19,06 & 20,30 & - & 147,00 & - & 7,55 & - & 28,00 & - & - & - & 6,02 & 8,34 & - \\
\hline $\mathrm{Sm}$ & - & 0.27 & 4,48 & 5,10 & - & 39.40 & - & 2,48 & - & 7.04 & - & - & - & 2,13 & 2.13 & - \\
\hline Eu & - & 0,37 & 1.38 & 1,46 & - & 9,78 & - & 0.84 & - & 1,96 & - & - & - & 0.87 & 1,15 & - \\
\hline Gid & - & 0,50 & 3,82 & 5.33 & - & 28,20 & - & 2,57 & - & 6.42 & - & - & - & 2,58 & 3,44 & - \\
\hline Dy & - & 0,62 & 2.91 & 5,03 & - & 22.50 & - & 2,34 & - & 4,78 & - & - & - & 2.59 & 3.48 & - \\
\hline $\mathrm{Er}$ & - & 0,56 & 1.61 & 3,33 & $\cdot$ & 11,60 & $\cdot$ & 1,53 & - & 2,78 & . & - & - & 1,89 & 2.52 & - \\
\hline $\mathrm{Yb}$ & - & 0,57 & 1,29 & 2,94 & - & 10,10 & - & 1,31 & - & 2,22 & - & - & - & 1.71 & 2,30 & - \\
\hline Lu & - & 0,10 & 0,18 & 0,46 & - & 1,33 & - & 0,20 & - & 0,31 & - & - & - & 0,26 & 0,40 & - \\
\hline
\end{tabular}

bos apresentam um mesmo intervalo de variação de $\mathrm{SiO}_{2},(\mathrm{MBM}$ $=42,98$ a 55,53\%; MAM $=45,20$ a 54,25\%) (Fig. 6). A maioria das amostras de ambos grupos se distribui preferencialmente no campo do basalto, subordinadamente do andesito basáltico, e a amostra ALS-6 (MBM) corresponde a picro-basalto.

$\mathrm{Na}$ figura 8 , as amostras do grupo MAM se classificam como basalto subalcalino $(2524 \leq \mathrm{R} 1 \leq 2896 ; 1999 \leq \mathrm{R} 2 \leq 2172)$ e as do grupo MBM se distribuem no mesmo campo ( $184 \mathrm{I} \leq \mathrm{R} 1 \leq 2434$; $2004 \leq \mathrm{R} 2 \leq 2062$ ), mas com representantes no campo do andesibasalto $(2040 \leq R 1 \leq 2819 ; 1592 \leq R 2 \leq 1805)$. A exemplo do que ocorre no diagrama da figura 6 , a amostra ALS-6 situa-se no campo do picrito $(\mathrm{R} 1=1906 ; \mathrm{R} 2=2381)$.

O diagrama de Jensen (1976) (Fig. 9) permite detalhar melhor ambos grupos, onde as amostras do grupo MAM situam-se preferencialmente no campo do basal to komatiítico, subordinadamente no do komatiito peridotítico. As amostras do grupo MBM distribuem-se nos campos dos Mg-toleiito (anfibolito) e do Fe-toleiito (piroxênio anfibolito-granulito máfico).

A composição normativa (CIPW) do anfibolito e da metamáfica analisados revela que a maioria das amostras contém proporções variadas de olivina e apenas duas contém quartzo e uma, nefelina (amostra ALS-6). Ao plotar esses valores no tetraedro dos basaltos de Yoder \& Tilley (1962) (Fig. 10), estas correspondem a olivina toleiitos (Fig. 10).

Com relação aos ETR, as oito amostras analisadas foram normalizadas aos valores do condrito $\mathrm{Cl}$ (Evensen et al. 1978) (Fig. 11). As amostras do grupo MAM, representadas por olivinaortopiroxênio anfibolito (ALS-2) e hornblenda xisto (ALS-I0, SOR13A e SOR-13D), apresentam em comum apenas as fortes anomalias negativas de $\mathrm{Ce}, \mathrm{com}$ valores de $\mathrm{Ce} / \mathrm{Ce}{ }^{*}$ variáveis entre 0,13 (ALS-10) e 0,67 (SOR-13A). O homblenda xistoé mais ricoem ETR total (ALS-10 $=1545,61 ;$ SOR-13A $=124,90 ;$ SOR-13D $=363,24) \mathrm{e}$ fracionamento de ETR maior $\left(\mathrm{La} / \mathrm{Lu}_{\mathrm{N}}-\mathrm{ALS}-10=6,84, \mathrm{SOR}-13 \mathrm{~A}=\right.$ 2,49 ; SOR-13D = 8,87; ) do que o olivina ortopiroxênio anfibolito, com valores de ETR total de $33,33 \mathrm{e} \mathrm{La} / \mathrm{Lu}_{N},=1,45$. Adicionalmente, a metaultramáfica (ALS 2) tem forte anomalia positiva de Eu $\left(\mathrm{Eu} / \mathrm{Eu}_{\mathrm{N}}=3,04\right)$ comparativamente ao hornblenda xisto $\left(\mathrm{Eu} / \mathrm{Eu}^{*}{ }_{\mathrm{N}}\right.$ $=0,86$ a 1,01$)$ e é mais pobre em terras raras intermediárias em relação às pesadas $\left(\mathrm{Gd} / \mathrm{Lu}_{N}=0,62\right)$, em contraste com as amostras de hornblenda xisto, nas quais $\mathrm{Gd} / \mathrm{Lu}_{N}$ varia de $1,60(\mathrm{SOR}-13 \mathrm{~A})$ a 2,64(ALS-10).

Por outro lado, no grupo MBM, o comportamento dos ETR nas amostras de anfibolito (SOR-21 e MAG-5) é distinto das amostras de ortopiroxênio anfibolito (ALS-6e ALS-7). As primeiras são

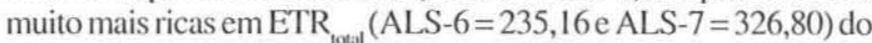
que as últimas (AMG-5 =159,72 e SOR-21 =120,06) e estas, por suqas vez, são mais ricas em ETRL do que ETRP $\left[\mathrm{La} / \mathrm{Lu}_{N}=6,48\right.$ (ALS-6) a 3,52 (ALS-7)] comparativamente ao anfibolito [La/Lu $=$ 1,05 (AMG-5) e 1,17 (SOR-21)]. Ressalte-se que também há diferenças significativas no comportamento dos ETR entre as amostras destes dois tipos petrográficos nos valores de $\mathrm{La} / \mathrm{Sm}_{\mathrm{N}}$ (ALS$6=1,58 ;$ ALS-7 = 1,93 e AMG-5=1,20; SOR-21=0,87), Gd/Lu $($ ALS$6=2,64 ;$ ALS-7 $=1,44$ e AMG-5=1,07; SOR-21 = 1,23) eEu/Eu* (ALS$6=1,00 ;$ ALS-7 $=0,85$ e AMG-5=1,29; SOR-21=1,13).

CONSIDERAÇÕES FINAIS A análise dos dados geológicos, petrográficos e geoquímicos obtidos a partir do estudo de um conjunto de amostras de anfibolitos e metaultramáficas coletadas na região entre as cidades paulistas de Socorro e Amparo, ao sul, e Itapira e Monte Sião, ao norte, permitiu caracterizar pelo menos quatro tipos petrográficos principais que se agrupam em litotipos com alto magnésio - MAM (olivina ortopiroxenito e anfibólio xisto) 
e baixo magnésio - MBM (ortopiroxênio anfibolito e anfibolito). As amostras do grupo MAM parecem definir trends de diferenciação magmática nos diagramas de variação, o que é reforçado pelos respectivbos padrões de ETR, compatíveis com fracionamento magmático a partir de protólitos ígneos subalcalinos e toleiiticos. Para testar esta hipótese, admitiu-se aque a amostra ALS-10 poderia derivar da SOR-13A por cristalização fracionada envolvendo minerais máficos, no caso a hornblenda. Sendo assim, os ETR têm comportamento de elementos incompatíveis em relação a esse mineral, com valores dos coeficientes de distribui-

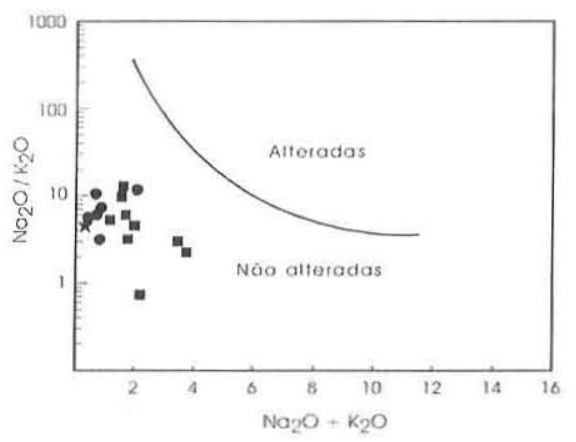

Figura 2 - Diagrama $\mathrm{Na}_{2} \mathrm{O}+\mathrm{K}_{2} \mathrm{O}$ vs. $\log \left(\mathrm{Na}_{2} \mathrm{O} / \mathrm{K}_{2} \mathrm{O}\right)$ segundo Myiashiro (1975). para discriminar rochas que passaram por alteraşão pós magmática. Círculos: $\mathrm{MgO}>10 \%$; quadrados: $\mathrm{MgO}<10 \%$; estrela: amostra ALS 2 (cumulato). ção (Kd) variável de aproximadamente 0,2 (para o La) a 0,64 (para o Dy) (Green \& Pearson 1985). Se considerarmos cristalização fracionada em desequilíbrio modal, para obter o enriquecimento destes elementos como observado na amostra ALS-10 em relação à SOR-13 (ex. $\mathrm{La}=5, \mathrm{Ce}=8, \mathrm{Nd}=8, \mathrm{Gd}=3$, etc) (Tabela $\mathrm{I}) \mathrm{s}$, seria necessária a cristalização de 95 a $98 \%$ deste mineral para que a composição do líquido residual se aproximasse da amostra ALS10, o que seria pouco provável. Além disso, as fortes anomalias negativas de $\mathrm{Ce}\left(\mathrm{Ce} / \mathrm{Ce}^{*}{ }_{N}=0,13\right.$ a 0,67$)$ nas rochas deste grupo, parecem envolver a crosta continental, seja na fase de geração do magma a partir do manto ou na de intrusão, como proposto em casos semelhantes por Heming \& Rankin (1979), Othman et al. (1989), Meen (1990) e Guy et al. (1999). Este aspecto parece também estar impressos nos diagramas multielemento, normalizados aos valores de N-MORB propostos por Sun \& McDonough (1989) (Figs. 12 e 13). Nestes diagramas, a título de comparação, está em destaque o padrão de distribuição da crosta continental superior e inferior (CCS e CCI), onde se observa, pelas assinaturas, que os magmas das rochas estudadas, em algum momento, parecem ter sido afetados, em diferentes intensidades, pela crosta continental, quer durante a evolução da fonte mantélica do protólito (assimilação crustal durante a subducção) ou durante a intrusão (contaminação crustal), especialmente no que tange ao comportamento de $\mathrm{Sr}, \mathrm{K}, \mathrm{Rb}$ e Ba.

Entretanto, nos mesmos diagramas, as amostras de metamáficas apresentam padrões bastante aleatórios, o que pode indicar alterações da composição das mesmas durante o metamorfismo
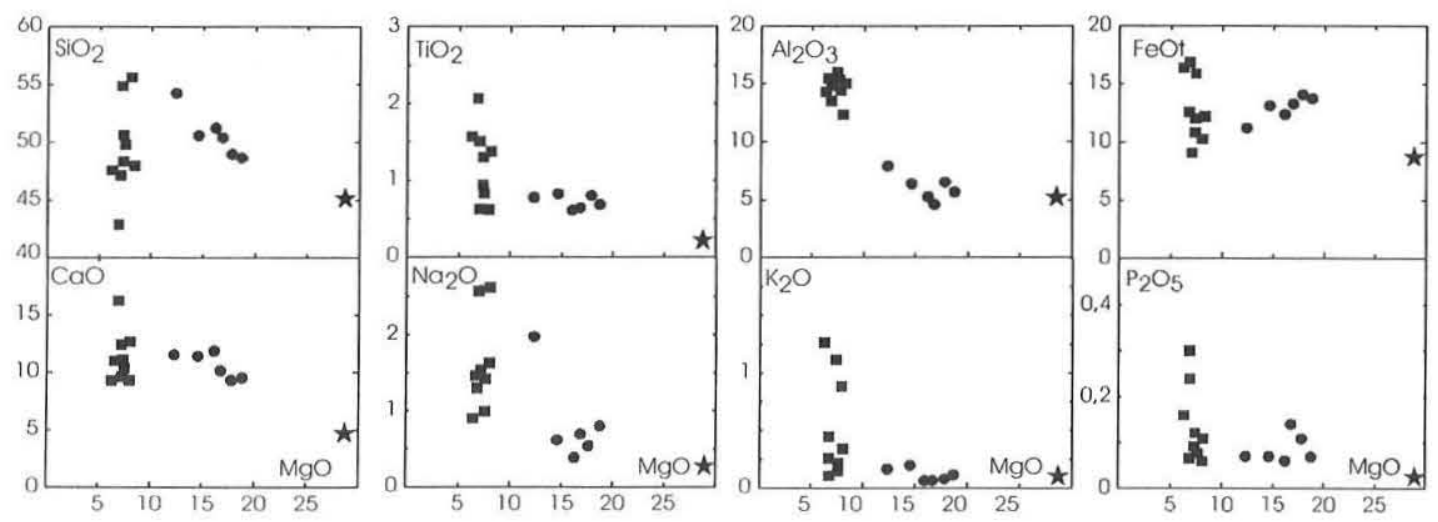

Figura 3 - Diagramas de variação química dos principais óxidos das rochas estudadas. Símbolos como na Figura 2
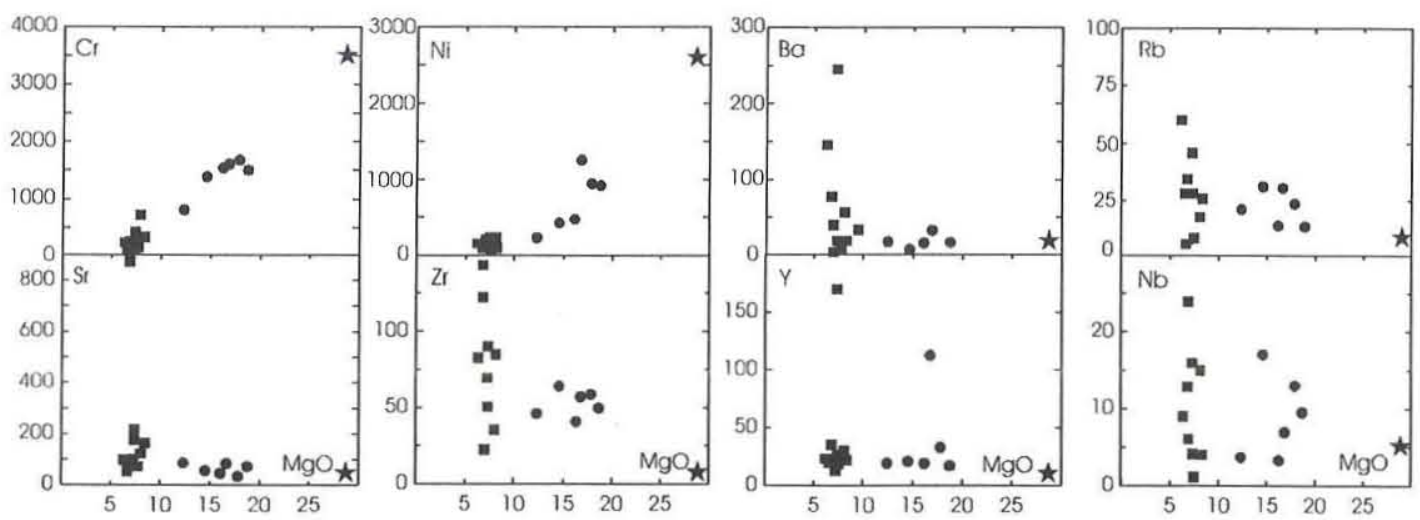

Figura 4 - Diagramas de variação para elementos traço das rochas estudadas. Símbolos como na Figura 2. 


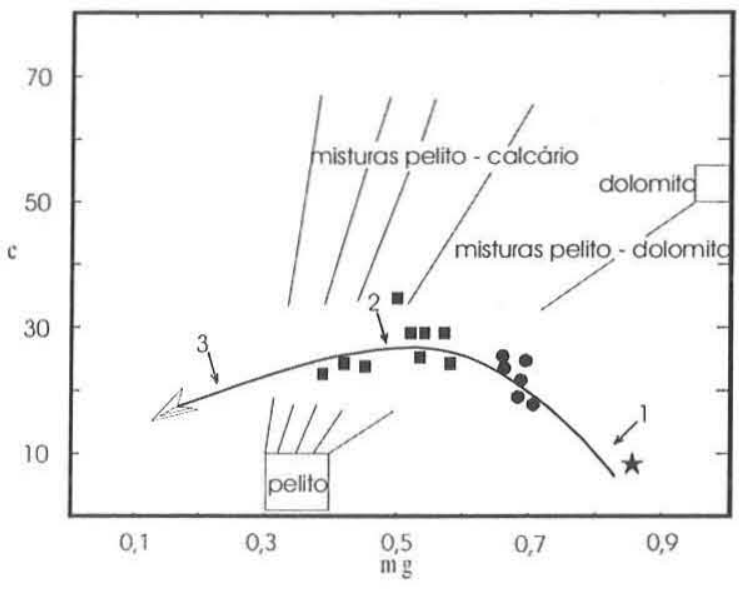

Figura 5 - Diagramas para a caracterização química da origem dos protolitos das rochas estudadas, segundo Leake (1964). Símbolos como na Figura 2. Os numerais 1, 2 e 3 correspondem respectivamente aos estágios da diferenciação iniciais ou cumulatos, intermediários e finais, dos doleritos do Karroo.

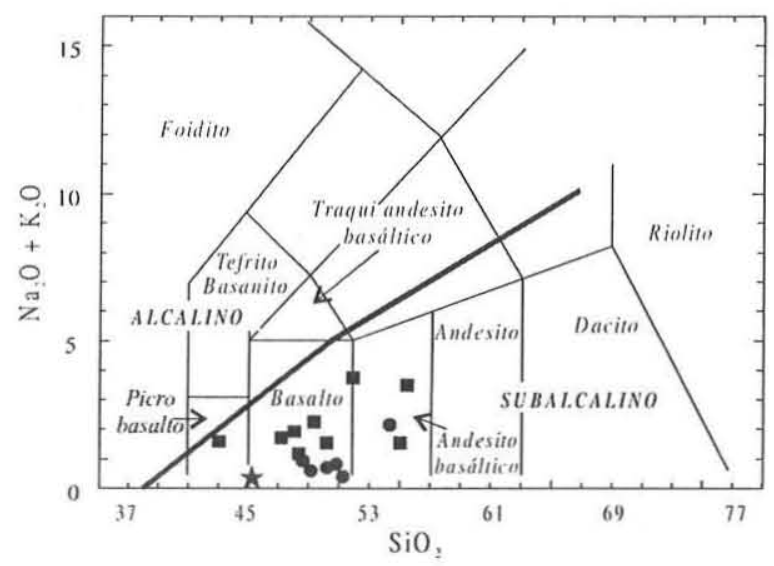

Figura 6 - Diagrama sílica vs. álcalis, mostrando classificação e nomenclatura das rochas estudadas (Irvine \& Baragar 1971; Le Bas et al. 1986). Símbolos como na Figura 2.

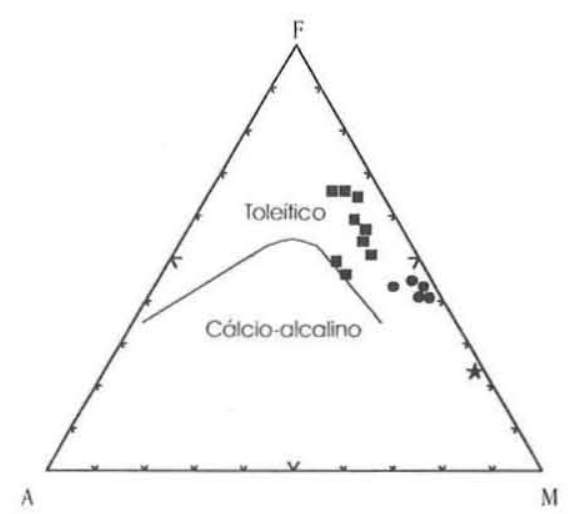

Figura 7 - Diagrama AFM para as rochas estudadas segundo Irvine \& Baragar (1971). Símbolos como na Figura 2. (metassomatismo), o que também parece ser evidenciado pelo padrão da amostra ALS-6 (grupo MBM), com filiação picrítica, embora não apresente evidências petrográficas para tanto.

Apesar destas constatações, nas figuras 13 e 14, onde também estão representados os padrões de basalto de ilhas oceânicas (BIO), basalto enriquecido de cadeia meio oceânica (E-MORB) e

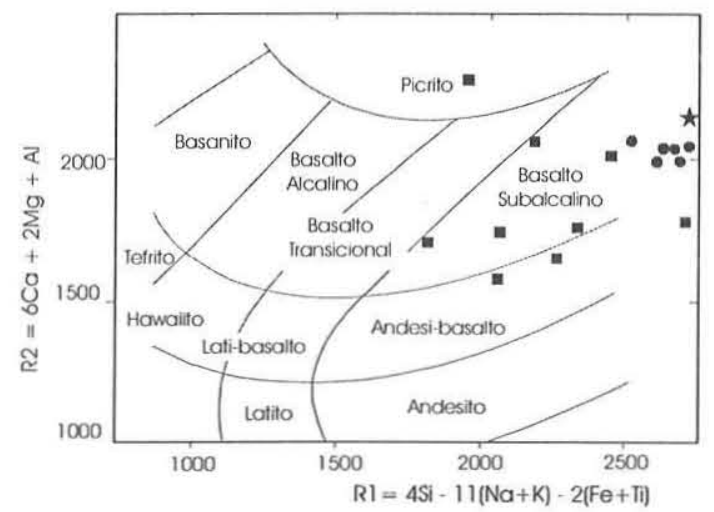

Figura 8 - Distribuição das rochas metamáficas e anfibolito no diagrama RI vs. R2 de De La Rocha et al. (1980). Símbolos como na Figura 2.

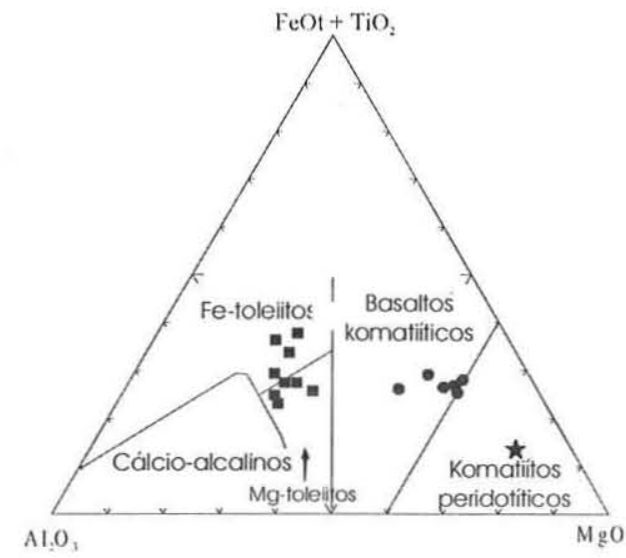

Figura 9 - Diagrama $\mathrm{Al}_{2} \mathrm{O}_{3}$ vs. $\mathrm{FeO}$, vs. $\mathrm{MgO}$ de Jensen (1976) para as rochas estudadas. Símbolos como na Figura 2.

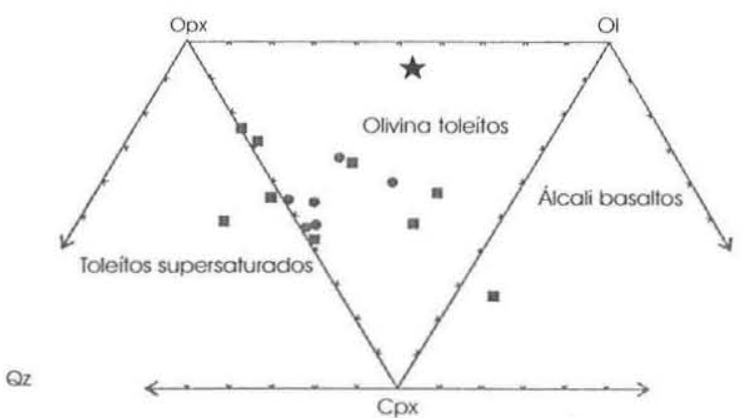

Ne

Figura 10 - Tetraedro de classificação dos basaltos segundo Yoder \& Tilley (1962), usando minerais normativos CIPW, com a maioria das amostras analisadas correspondendo a olivina toleiitos. Símbolos como na Figura 2. 
da crosta continental superior e inferior (Weaver \& Tarney 1984), observa-se que as rochas estudadas têm uma tendência geral comparável com E-MORB, exceto ALS-2, metaultramáfica e possível cumulato, cuja tendência situa-se abaixo do conjunto principal.

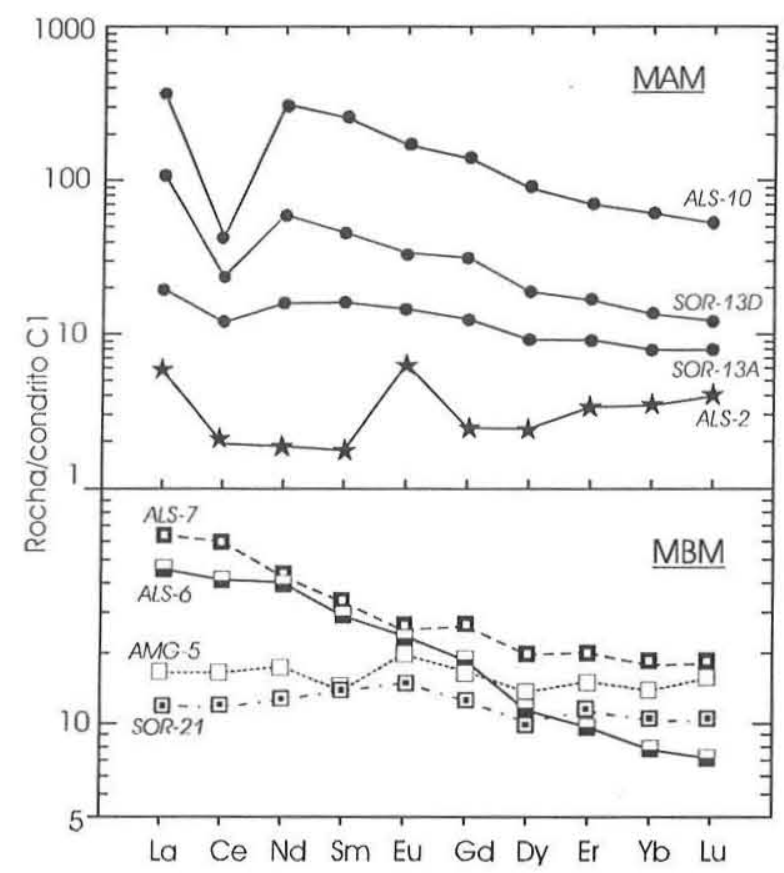

Figura 11 - Padrões de abundância dos elementos terras raras normalizados pelo condrito segundo Evensen (1978), para as amostras estudadas. Símbolos como na Figura 2

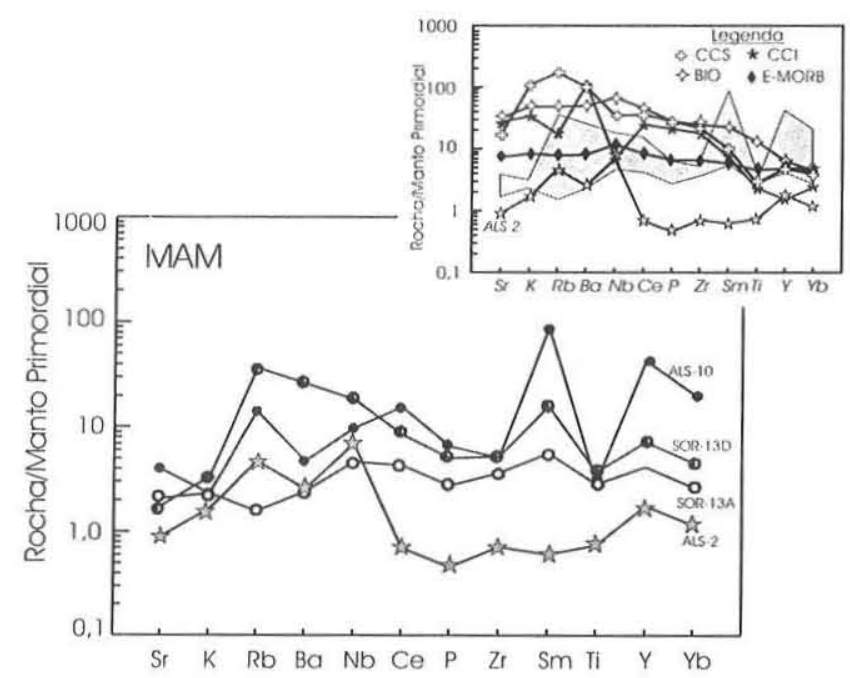

Figura 12 - Padrões de distribuição de elementos incompatíveis normalizados pelo manto primitivo de Sun \& McDonough (1989), para amostras de hornblenda xisto e metaultramáfica do grupo alto $\mathrm{MgO}$ (MAM). No destaque, a área sombreada equivale ao intervalo de variação para estas rochas e, para comparação, encontram-se os padrões de distribuição para rochas de diferentes ambientes geotectônicos: CCS - crosta continental superior; $\mathrm{CCI}$ - crosta continental inferior: $\mathrm{BIO}-$ basalto de ilha oceânica.

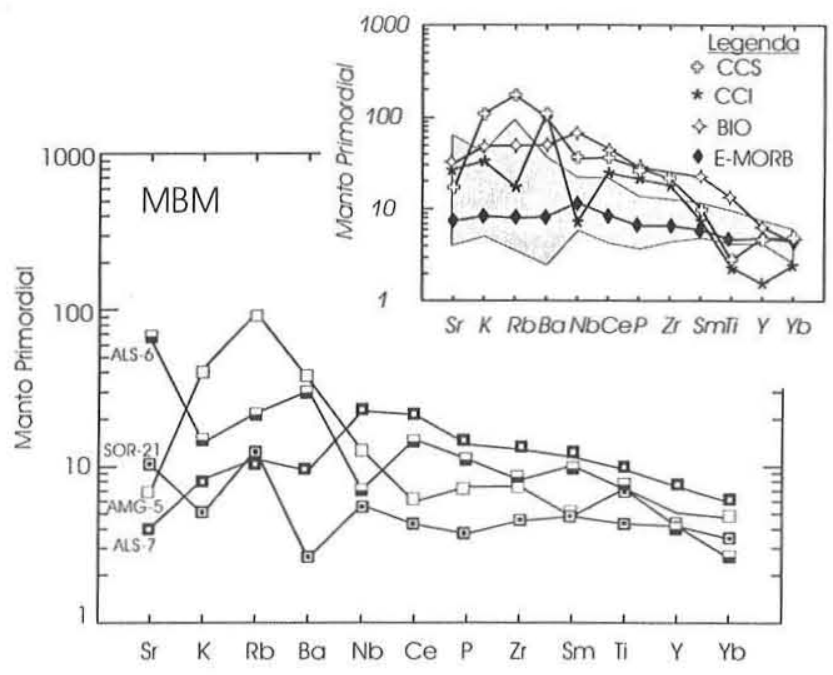

Figura 13 - Padrões de distribuição de elementos incompatíveis normalizados pelo manto primitivo de Sun \& McDonough (1989), para amostras de anfibolito e granulito máfico do grupo baixo $\mathrm{MgO}(\mathrm{MBM})$. No destaque, a área sombreada equivale ao intervalo de variação para estas rochas e para comparação, encontram-se os padrões de distribuição para rochas de diferentes ambientes geotectônicos, conforme indicado na Figura 12.

Quanto à gênese dessas rochas, pouco se pode adiantar. É apenas evidente uma afinidade com associações do tipo E-MORB. Uma hipótese de origem komatítica foi aventada por Peloggia (1990) para a metamáfica e metaultramáfica (hornblenda xisto) da região de Arcadas, situada a sudoeste de Amparo. Apesar da proximidade e semelhança do material estudado pelo autor, não há, na área ora estudada, evidências que confirmem essa origem. Por outro lado, Zanardo (1987) levanta a possibilidade de que parte desse material possa representar fragmentos de crosta oceânica (restos de ofiolito), ligados à colisão responsável pelo pacote vulcanossedimentar do Grupo Itapira, com base na presença das metaultramáficas com anomalias negativas de Ce e elevados teores de $\mathrm{Cr}$ e Ni. Essa hipótese, no entanto, não se sustenta nas evidências de participação da crosta continental, seja na origem ou na evolução destas rochas.

$\mathrm{O}$ presente estudo mostra que etapas futuras devem incluir o detalhamento de cada grupo aqui definido, com caracterização geoquímica, isotópica e de química mineral das ocorrências mais importantes, com vistas à datação e evolução petrológica, para melhor situá-los no contexto dos Complexos Amparo e Itapira.

Agradecimentos À FAPESP, pelo suporte financeiro e bolsas de iniciação científica s(Processos 90/3948-1; 95/1051-8; 96/00881-0) e aos revisores da RBG pelas sugestões ao manuscrito.

\section{Referências}

Almeida F.F.M., Hasui Y., Brito Neves B.B.,Fuck R.A. 1981. Brazilian structural provinces: an introduction. Earth Sci. Rev., 17:1-29.

Artur A.C. 1980. Rochas metamórficas dos arredores de Itapira, Sp. Dissertação de Mestrado, Instituto de Geociências, 
Universidade de São Paulo, 193 p.

Artur A.C. 1988. Evolução policíclica da infra-estrutura da porção sul do estado de Minas Gerais e áreas adjacentes do estado de São Paulo. Tese de Doutoramento, Instituto de Geociências, Universidade de São Paulo, 231 p.

Campos Neto M.C., Basei M.A.S., Alves F.R, Vasconcelos A.C.B. 1984. A nappe de cavalgamento Socorro (SP-MG). In: SBG, Congr. Bras. Geol., 33, Rio de Janeiro, Anais, 4:1809-1822

Campos Neto M.C. 1985. Evolução do pré-cambriano paulista e regiões adjacentes. In: SBG, Simp. Reg. Geol., 4, São Paulo, Atas, p. 79-80

De La Roche H., Leterrier J., Grandclaude P., Marchal M. 1980. A classification of volcanic and plutonic rocks using R1-R2 diagram and major element analyses. Its relationship with current nomenclature. Chem. Geol., 29:183-210.

Ebert H. 1968. Ocorrência da facies granulítica no sul de Minas Gerais e áreas adjacentes, em dependência da estrutura orogenética: hipótese sobre a sua origem. An. Acad. Bras. Ciec., 40:215-229.

Ebert H. 1971. Os Paraibides entre São João Del Rei, Minas Gerais e Itapira, São Paulo, e a bifurcação entre Paraibides e Araxaides. São Paulo. SBG, Boletim Especial, 1:177-178.

Evensen N.M., Hamilton P.J., O'nions R.K. 1978. Rare earth abundances in chondritic meteorits. Geochim. Cosmochim. Acta. 42: 1199-1212.

Freitas F.C. 2000. Geotermobarometria é evoluşão metamórfica das rochas granulíticas da região de Socorro, SP. Dissertação de Mestrado, Instituto de Geociências, USP, 175 p.

Green T.H. \& Pearson N.J. 1985. Experimental determination of of REE partition coefficients between amphibole and basaltic liquids at high pressure. Geochim. Cosmochim. Acta, 49:1465-1468.

Guy C., Daux V., Schott J. 1999. Behavior of rare earth elements during sea water/basalt interactions in the Mururoa Massif. Chem. Geol., 158:21-35.

Hanson G.N. 1980. Rare earth elements in petrogenetic studies of igneous systems. Annu. Rev. Earth Planet. Sci., 8:371-406.

Hasui Y. \& Oliveira M.A.F. 1984. Província Mantiqueira-Setor Central. In F.F.M. Almeida \& Y. Hasui (Coord.) O Pre-Cambriano do Brasil. São Paulo, Edgard Blucher, pp.: 308-339.

Irvine T.N. \& Baragar W.R.A. 1971. A guide to the chemical classification of the common volcanic rocks. Can. Jour: Earth Sci., 8:523-548.

Jensen L.S. 1976. A new cation plot for classifying subalcaline volcanic rocks. Ontario Division of Mines, Misc., Paper 66, 22 p.

Heming R.F. \& Rankin P.C. 1979. Ce-anomalous lavas from Rabaul Caldera, Papua New Guinea. Geochim. Cosmochim. Acta., 43:1351-1355.

Lazarini A.P. 2000. Petrologia de metabasitos/ultrabasitos da região de Águas de Lindóia. Dissertação de Mestrado, Instituto de Geociências e Ciências Exatas, Universidade Estadual Paulista, 134 p.

Le Bas M.J., Le Maitre R.W. Strekeisen A., Zanettin B. 1986. A chemical classification of volcanic rocks based on the total alkali-silica diagram. Jorn. Petrol., 27: 745-750.

Leake B.E. 1964. The chemical distinction between ortho and para amphibolites. Jour: Petrol., 5: 238-254.

Ludden J.N. \& Thompson G. 1978. Behavior of rare earth elements during submarine weathering of tholeiitic basalt. Nature, 274:147-149.
Meen J.K. 1990. Negative Ce anomalies in Archean amphibolites and Laramide granitoids southwestern Montana, U.S.A. Chem. Geol.. 81:191-207.

Miyashiro A. 1975. Classification, characteristics and origin of ophiolites. Jour: Geol., 83:249-281.

Othman D.B., White W.M., Patchett J. 1989. The geochemistry of marine sediments, island arc genesis and crust-mantle recycling. Earth Planet. Sci. Lett., 94:1-21.

Pearce J.A. 1983. Role of sub-continental lithosfere in magma genesis at active continental margins. In C. J. Hawkesworth and M. J. Norry (ed.) Continental basalts and mantle xenoliths. Shiva, Nantwich, 230249.

Peloggia A.U.G.1990. A Faixa Alto Rio Grande na região de Amparo $(S P)$. Dissertação de Mestrado, Instituto de Geociências, Universidade de São Paulo, 124 p.

Sun S.S. 1980. Lead isotopic study of young volcanic rocks from midocean ridges, ocean islands and islands arcs. Phil. Trans. R. Soc. London, A297:409-445.

Sun S.S. \& McDonough W.F. 1989. Chemical and isotopic systematics of oceanic basalts for mantle composition and process. In: A.D. Saunder, \& M.J. Norry (ed.) Magmatism in the ocean basins. Geological Society, Special Publication, 42:313-345.

Tassinari C.C.G. \& Campos Neto M.C. 1988. Precambrian continental crust evolution of Southeastern São Paulo State, Brazil, based on isotopic evidences. Geochim. Brasiliensis, 2:175-183.

Weaver B. L. \& Tarney J. 1984. Empirical approach to estimating the composition of the continental crust. Nature, 310:575-577.

Wernick E. 1967. A geologia da região de Amparo, leste do estado de São Paulo. Tese de Doutoramento, Fac. Fil. Ci. Let., Rio Claro, SP, 107 p.

Wernick E. 1978. Contribuição à estratigrafia do Pré-cambriano do leste do estado de São Paulo e áreas vizinhas. Rev. Bras. Geoc., 8:206-216.

Wernick E. \& Penalva F. 1973. As relações entre os grupos Amparo e Itapira (SP). In: SBG, Congr. Bras. Geol., 27, Aracaju, Boletim Especial, 1:116-117

Wernick E. \& Artur A. C. 1983. Evolução policíclica dos terrenos Arqueanos no leste do estado de São Paulo e sul de Minas Gerais. In: SBG/Núcleo Minas Gerais, Simpósio de Geologia de Minas Gerais 2, Belo Horizonte, Atas, 50-61

Wernick E., Oliveira M.A.F., Kawashita K., Cordani U.G., Delhal, J. 1976. Estudo geocronológico pelo método $\mathrm{Rb} / \mathrm{Sr}$ em rochas do bloco Jundiaí e regiōes adjacentes. Rev. Bras. Geoc, 6:125-135.

Winchester J.A., Park R.G., Holland J.G. 1982. The geochemistry of Lewisian semipelitic schists from the Gairloch District, Western Ross. Scott. Jour: Geol., 16:165-179.

Yoder H.S. \& Tilley C.E. 1962 Origin of basalts magmas: an experimental study of natural and synthetic rock systems. Jour: Petrol., 3:342-532.

Zanardo A. 1987. Análise petrológica e microestrutural das rochas da folha Águas de Lindóia. São Paulo. Dissertação de Mestrado, Instituto de Geociências, Universidade de São Paulo, 270 p.

Manuscrito A-1437

Recebido em 30 de maio de 2003

Revisão dos autores em 25 de abril de 2004 Revisão aceita em 20 de maio de 2004 